\title{
Genetics of Severe Cutaneous Adverse Reactions
}

\author{
Shang-Chen Yang ${ }^{1}$, Chun-Bing Chen 1,2,3,4,5,6,7, Mao-Ying Lin ${ }^{1}$, Zhi-Yang Zhang ${ }^{1}$, \\ Xiao-Yan Jia ${ }^{8}$, Ming Huang ${ }^{8}$, Ya-Fen Zou ${ }^{8}$ and Wen-Hung Chung $1,2,3,4,5,7,9,10,11 *$
}

${ }^{1}$ Department of Dermatology, Xiamen Chang Gung Allergology Consortium, Xiamen Chang Gung Hospital, Xiamen, China, 2 Department of Dermatology, Drug Hypersensitivity Clinical and Research Center, Chang Gung Memorial Hospital, Taoyuan, Taiwan, ${ }^{3}$ Cancer Vaccine and Immune Cell Therapy Core Laboratory, Department of Medical Research, Chang Gung Memorial Hospital, Taoyuan, Taiwan, ${ }^{4}$ College of Medicine, Chang Gung University, Taoyuan, Taiwan, ${ }^{5}$ Whole-Genome Research Core Laboratory of Human Diseases, Chang Gung Memorial Hospital, Keelung, Taiwan, ${ }^{6}$ Graduate Institute of Clinical Medical Sciences, Chang Gung University, Taoyuan, Taiwan, ${ }^{7}$ Immune-Oncology Center of Excellence, Chang Gung Memorial Hospital, Linkou, Taiwan, ${ }^{8}$ Department of Neurology, Xiamen Chang Gung Hospital, Xiamen, China, ${ }^{9}$ Department of Dermatology, Beijing Tsinghua Chang Gung Hospital, School of Clinical Medicine, Tsinghua University, Beijing, China,

${ }^{10}$ Department of Dermatology, Ruijin Hospital, School of Medicine, Shanghai Jiaotong University, Shanghai, China,

${ }^{11}$ Genomic Medicine Core Laboratory, Chang Gung Memorial Hospital, Linkou, Taiwan

Severe cutaneous adverse reactions (SCARs) including Stevens-Johnson syndrome (SJS), toxic epidermal necrolysis (TEN), and drug rash with eosinophilia and systemic symptoms (DRESS) are $T$ cells-mediated life-threatening immune reactions, most commonly induced by drug. The last decade has seen significant progress in SCARs research. Recent studies have unveiled the pathogenesis of SCARs involved in susceptible genes, including human leukocyte antigens (HLA) and drugs-T cell receptor (TCR) interaction that may trigger $T$ cell activation with downstream immune signaling of cytokines/chemokines and specific cytotoxic proteins releases. Advances in identification of multiple genetic alleles associated with specific drugs related SCARS in different populations is an important breakthrough in recent years for prevention of SCARs. This article summarized the findings on genetic factors related to SJS/TEN, especially for HLA.

Keywords: genetic screen, Stevens-Johnson syndrome, toxic epidermal necrolysis, pharmacogenomic, severe cutaneous adverse drug reactions

\section{INTRODUCTION}

Cutaneous reactions are most common manifestations seen in hypersensitivity reactions of drugs, named cutaneous adverse drug reactions, and among those with risk of life-threatening are classified into severe cutaneous adverse reactions (SCARs), mediated by drug-specific T lymphocytes, including drug rash with eosinophilia and systemic symptoms (DRESS)/druginduced hypersensitivity syndrome (DIHS), Stevens-Johnson syndrome (SIS), and toxic epidermal necrolysis (TEN). The mortality rates for SJS/TEN are 5-10\% in SJS and 30-50\% in TEN (1), and the common leading culprit drugs around the world are antibiotics, antiepileptics, allopurinol, and cold medicine (2-4). In this article, we reviewed the updated molecular mechanism and susceptible genes related to SCARs.

\section{Immune Mechanisms and Clinical Manifestations of Severe Cutaneous Adverse Reactions}

SCARs belonged to type IV hypersensitivity reaction and are $\mathrm{T}$ cell-mediated immune responses with different effector cells and cytokines, resulting in further subtypes with specific clinical features. 
SJS/TEN is characteristic for cutaneous and mucosal detachment, commonly including oral, ocular, and genital or anal mucosae. Internal epithelial organs are rarely involved, concerning mainly in the respiratory and gastrointestinal tract (5). SJS/TEN is one of the representative SCARs with high mortality and complications, where CD8+ cytotoxic T lymphocytes (CTLs) play a role, acting as effector cells with nature killer cells, causing cell death by the participant of perforin/granzyme B, granulysin, and/or Fas-Fas ligand (6). Besides, cytokines/chemokines, including interleukin (IL)-6, IL-8, IL-15, C-C chemokine receptor 10, tumor necrosis factor- $\alpha$, interferon- $\gamma$, etc., also contribute to these severe immune reactions (7). The messenger RNA expression and level of 15$\mathrm{kDa}$ granulysin were found much higher than others in SJS/TEN blister cells, suggesting it is the key mediator of disseminated keratinocyte apoptosis (8).

Another severe phenotypes of SCARs is DRESS, presenting as long-lasting, widespread, and infiltrated skin rash with internal organ involvement and hematological abnormalities, most frequently as eosinophilia and atypical lymphocytes (9). The immune mechanism involved in DRESS is majorly the Th2 immune response. Th2 cells involved in DRESS secrete ILs, including IL-5, IL-4, and IL-13, promoting immunoglobulin $\mathrm{E}$ and immunoglobulin $\mathrm{G} 4$ production and macrophage deactivation, leading to mast cell and eosinophil activation (6). Perforin/granzyme B, tumor necrosis factor- $\alpha$, interferon- $\gamma$, C-C chemokine receptor 4, and thymus and activation-regulated chemokine (10) are also engaged.

\section{Molecular Mechanism and Susceptible Genes Related to Severe Cutaneous Adverse Reactions}

Roujeau et al. firstly reported the relationship between human leukocyte antigen (HLA) and SJS in 1986 (11) and HLA and TEN in 1987 (12). The association of HLA and SCARs are drug-specific and ethnicity-specific (13). Specific HLA is not only a genetic marker but also plays an important role in the pathogenesis of SCARs by presenting drug antigen to $\mathrm{T}$ cell receptor (TCR) and causing $\mathrm{T}$ cell-dependent immune response (14).

Recent advance in the technology of pharmacogenomic studies have showed more genetic risk factors associated with SCARs, not only in genes of HLA and other immune pathways, but also in drug metabolism or elimination. The genetic approach for the pharmacogenomics studies for SCAR has been evolved from sequencing based genotyping with polymerase chain reaction (PCR), such as HLA genotypes (15) to more comprehensive approaches, including genome-wide association study (GWAS) and next-generation sequencing (NGS), in discovering the relationship between adverse drug reactions (ADRs) and genotyping, and discovered more non-HLA loci (15-17).

\section{Genetic Susceptibility to Aromatic Antiepileptic Drug-Induced Severe Cutaneous Adverse Reactions}

Aromatic antiepileptic drugs (AEDs) are commonly used mainly in treating epilepsy and neuralgia, including carbamazepine (CBZ), oxcarbazepine (OXC), lamotrigine (LTG), phenytoin (PHT), and phenobarbital (PB). A strong association of HLA-B* 15:02 with CBZ-induced SJS/TEN was first found in Han Chinese (18). This relationship was also proved in Southeast Asians, including Thais (19), Malaysians (20), Indians (21).

AEDs had the same chemical structure, an aromatic ring, thus sharing the same risk allele. The susceptibility of $H L A-B^{*} 15: 02$ with AED-induced SJS/TEN was also found in PHT (22) and OXC (23), causing SJS/TEN in Han Chinese and Southeast Asians (24-26) (Table 1).

By using GWAS approach, our previous study found that CYP2C9*3 was significantly related to PHT-induced SCARs in Han Chinese, Japanese and Malaysian, and by adding HLA-B ${ }^{\star} 15: 02$ to this variant could increase sensitivity for preemptive test (35). In addition to $H L A-B^{*} 15: 02, H L A-B^{*} 13: 01$, and $H L A-B^{*} 51: 01$ were also found strong association with PHT-induced SCARs in Han Chinese, Thai and Japanese (37). Another genetic variant for PHT-induced SCARs was HLA-B*15:13, which majorly found in Malaysian (24) (Table 1).

The HLA-DRB1*15:01 allele had been reported to be associated with AED-induced SJS/TEN in Han Chinese (68). Besides, HLA-A*33:03, HLA- $B^{*}$ 58:01, HLA- $B^{*} 40: 01$, and HLADRB1*03:01 alleles had also been reported to be associated with AED-induced SJS/TEN $(68,69)$.

There were differences of susceptible genes among ethnic groups. The same susceptible genotype of HLA-B*15:02 of CBZ-induced SJS/TEN was not found in Northeast Asians like Japanese and Korean, but HLA-B*15:11 instead (27, 28, 63). Interestingly, association between $H L A-B^{\star} 15: 21$ and CBZinduced SJS was found in an $H L A-B^{*} 15: 02$ negative Thai patient (29). The relationship of $H L A-B^{*} 15: 11$ and $H L A-B^{*} 15: 21$, member of HLA-B75 serotype, and CBZ-induced SJS/TEN was found in $H L A-B^{*} 15: 02$ negative patients with pooled-data of Southeast Asian (29) (Table 1).

As for other AEDs in Northeast Asians, HLA-B*51:01 was found to be related to PHT- and PB-induced SJS/TEN, and HLA$\mathrm{A}^{*}$ 02:07 was found to be relevant with $\mathrm{PB}$ - and zonisamideinduced SJS/TEN (36) (Table 1).

Caucasians also revealed less relevant of AEDs and HLA$B^{*} 15: 02$, instead, they were commonly found with $H L A-A^{*} 31: 01$, and developed CBZ-induced DRESS $(31,32)$. This relationship also existed in Han Chinese and Japanese (31, 70), however, not only DRESS but also SJS/TEN were related with this gene in Japanese (70). Another Caucasian-specific gene was HLA-B*57:01 and was found to be strongly associated with CBZ-induced SJS/TEN in Europeans (30). A limited number also showed a relationship with HLA-B* 38 and LTG-induced SJS/TEN (34) (Table 1). 
TABLE 1 | Genetic associations with SCARs in different populations.

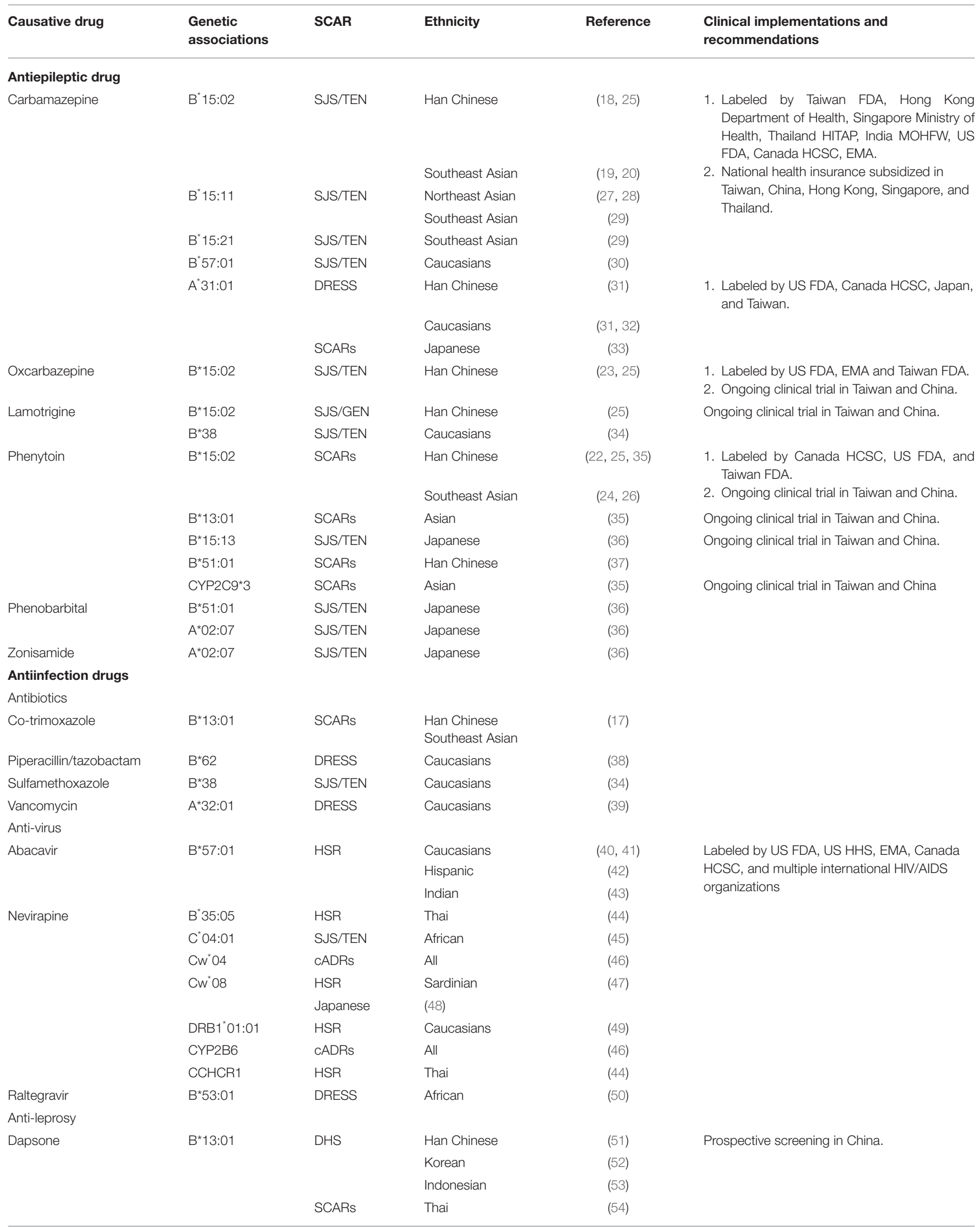


TABLE 1 | Continued

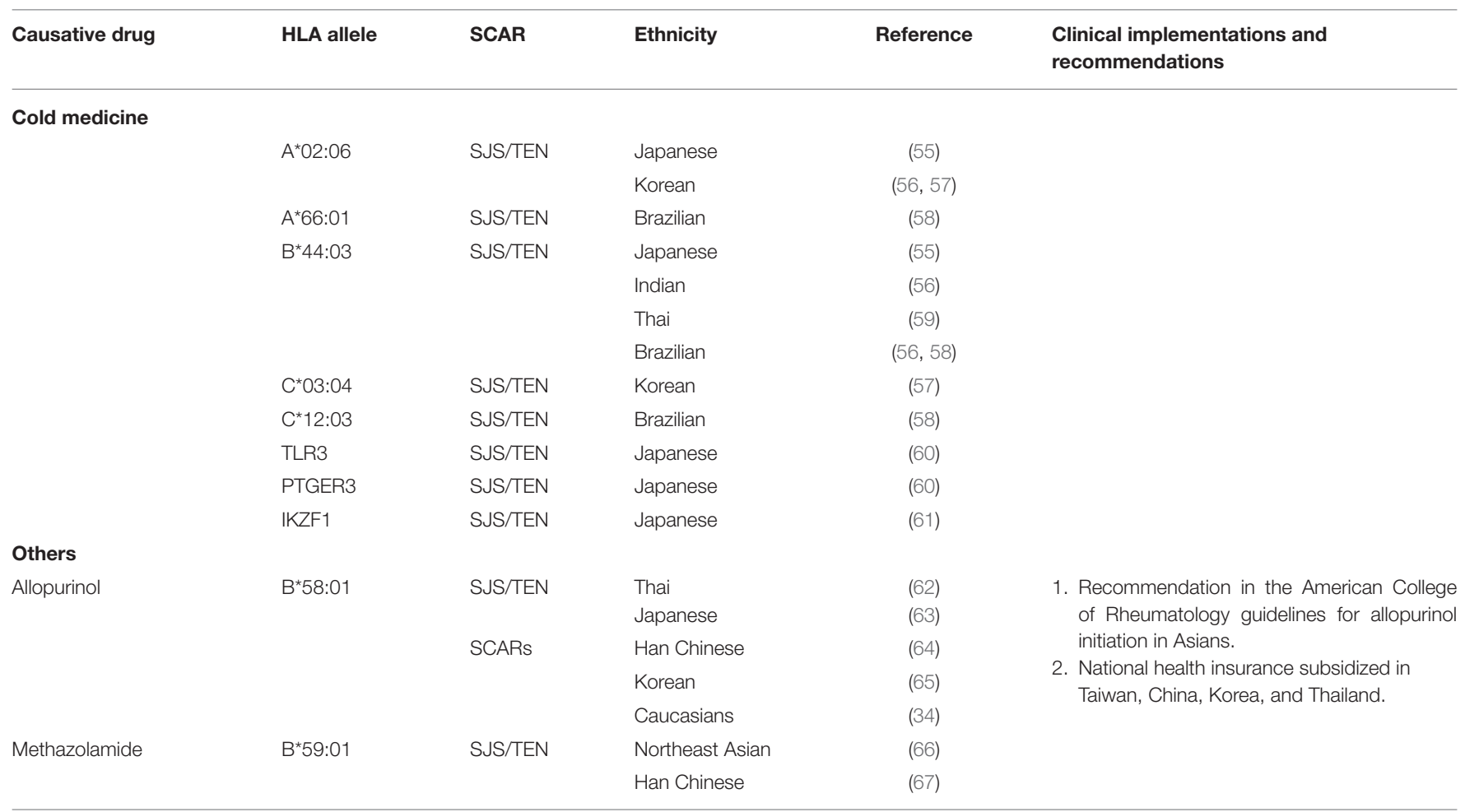

DHS, Dapsone hypersensitivity syndrome; HSR, hypersensitivity reaction.

\section{Genetic Susceptibility to Antibiotics Induced Severe Cutaneous Adverse Reactions}

Antibiotics are one of the most widely used medications, being responsible for one-fifth to one-third of ADRs (71, 72). The most common cause of SCARs induced by antibiotics are beta-lactams; others include sulphonamide antibiotics, fluoroquinolones, macrolides, tetracyclines, and glycopeptides (71). Above all, vancomycin is notable for causing DRESS. The relevant susceptible gene found with vancomycin-causing DRESS was HLA-A*32:01, with a strong association in Caucasians (39). Other possible genes as a risk factor in Caucasian were $H L A-B^{*} 38$ with sulfamethoxazole-induced SJS/TEN (34) and HLA-B*62 with piperacillin/tazobactam-induced DRESS (38), yet further research is still needed due to number limitation (Table 1).

Antibiotics, AEDs, and allopurinol are the most common offending drugs causing SJS/TEN in China from our previous study (4). Although the finding of genetic susceptibility with antibiotic-induced SCARs was limited, our recent study by using whole genome sequencing (WGS) approach showed HLA$B^{*}$ 13:01, not metabolism enzymes, was strong associated with cotrimoxazole-induced SCARs in Asians, including Han Chinese, Thai, and Malaysian (17) (Table 1).

Dapsone is mainly used in the treatment of leprosy and can also apply in other dermatological inflammatory diseases due to the ability of anti-infection and anti-inflammation. Dapsone hypersensitivity syndrome is the potentially fatal adverse effect of dapsone, presenting as fever, skin rash, lymphadenopathy, and multiple systemic involvements. By using GWAS approach, the susceptible gene of DHS was first found in Han Chinese with HLA-B*13:01 (51), which mainly exists in Asians. The same result was validated in Koreans (52) and Indonesians (53). This gene was also susceptible in Thai with dapsone-induced SCARs (54), including DRESS and SJS/TEN (Table 1).

\section{Genetic Susceptibility to Antivirus Induced Hypersensitivity Reactions}

Abacavir is a nucleoside reverse transcriptase inhibitor and is used as one of the combination treatment of human immunodeficiency virus (HIV) infection. Hypersensitivity reactions induced by abacavir appear in $\sim 5-8 \%$ of Caucasians (73), which presented as fever, rash, gastrointestinal tract, and respiratory symptoms during the first 6 weeks of initiation. These symptoms are non-specific; however, being a delayed-type immune reaction, a patch test can easily help to distinguish hypersensitivity reactions (73). The relevant susceptible gene HLA-B* ${ }^{*} 7: 01$ was found in white and black population $(40,41)$, especially white (74), and also Hispanic (42) and Indian children (43). A study in Hong Kong found a $0.5 \%$ positive rate with HLA-B*57:01 in HIV-positive patients of Han Chinese, thus suggesting that screening in this population is unnecessary (75) (Table 1).

Nevirapine is a nun-nucleoside reverse transcriptase inhibitor (NNRTI), and is also a medication treating HIV infection. 
The association of susceptible gene was first found with HLA$D R B 1^{*}$ 01:01 in nevirapine-induced HSR in Western Australian (49). However, this gene was later proven more associated with hepatotoxicity rather than cADRs in Caucasian (46). Other susceptible gene found in nevirapine-induced hepatotoxicity were $H L A-C w^{*} 08$ in Japanese (29), $H L A-C w^{*} 04$ in Han Chinese (76), and $H L A-D Q B 1^{*} 05$ in Caucasian (46). Both $H L A-C w^{*} 08$ and $H L A-C w^{*} 04$ were found relevant to nevirapine-induced HSR and hepatoxicity. Relationships between $H L A-C w^{*} 08$ and HSR were found in Sardinian (47) and Japanese (29). $H L A-C w^{*} 04$ was found commonly in nevirapine-induced cADRs in Han Chinese, Thai, Spain, African and Caucasian, especially African and Asian (46). CYP2B6 was also participated due to affecting delayed plasma clearance of nevirapine (46). Besides, $H L A-B^{*}$ 35:05 was found to be predictable with nevirapine-induced skin rash in Thai (44), whereas the same relationship was found weak in Han Chinese and Caucasian (46). In addition to HSR, SJS/TEN was found in patients using nevirapine, associated with $H L A-C^{*}$ 04:01 in African (45), and recently, the association between genetic variations in CCHCR1 and nevirapine-induced HSR was also found in Thai (77). GWAS approach was used in both studies (Table 1).

Raltegravir is an integrase inhibitor that is also used in the treatment of HIV infection, and HLA-B*53:01 was found strongly associated with raltegravir-induced DRESS in Africans (50) (Table 1).

\section{Genetic Susceptibility to Cold Medicine Induced Stevens-Johnson Syndrome and Toxic Epidermal Necrolysis}

The term cold medicine comprises non-steroidal antiinflammatory drugs and other multi-ingredient medications. Due to the high prevalence of cold and the use of cold medicine, SJS/TEN developed after patients using cold medicines is not uncommon, and a series of susceptible genes had been reported to be related to cold medicine-induced SJS/TEN, especially with severe ocular complications. The association of HLA$\mathrm{A}^{*}$ 02:06 and HLA-B*44:03 was found to be associated with cold medicine-induced SJS/TEN in Japanese (55), and the same susceptible genes were verified in patients of other populations, such as HLA-B*44:03 in Indian and Brazilian, and HLA*02:06 in Korean (56). Besides, HLA-C*03:04 was also reported to be associated with cold medicine-induced SJS/TEN in Korean (57). Furthermore, HLA-A*66:01 and HLA-C*12:03 was found related in Brazilian (58) and HLA-B*44:03 and HLA-C*07:01 found in Thai (59). In summary, HLA-B*44:03 seems to be a cross-ethnic susceptible gene with a strong association in Japanese, Brazilian, Indian, and Thai, whereas HLA-A*02:06, HLA-B*44:03, tolllike receptor 3 (TLR3), prostaglandin-E receptor 3 (PTGER3), and IKZF1, by using GWAS approach, were identified as primary association to cold medicine-induced SJS/TEN with severe ocular involvement in Japanese $(55,60,61,78)$ (Table 1).

\section{Genetic Susceptibility to Allopurinol-Induced Severe Cutaneous Adverse Reactions}

By inhibiting xanthine oxidase and then reducing the synthesis of uric acid, allopurinol is a first-line drug used to treat hyperuricemia and gout and also remains to be one of the leading causes of SCARs. HLA-B*5801 was first found as an important genet marker of allopurinol-induced SCARs in Han Chinese (64). The same associations were validated in Thai (62), Japanese (63), Korean (65), and Caucasians (34). However, the pharmacogenomic associations varied from different ethnic populations, $50-60 \%$ in Caucasians and Japanese, and $80-100 \%$ in Korea, Thai, and Han Chinese (79). Other non-genetic factors may also contribute to allopurinol-induced SCARs, especially impaired renal function, cardiovascular diseases, and higher drug initiating dosages (80) (Table 1).

\section{Genetic Susceptibility to Methazolamide-Induced Stevens-Johnson Syndrome and Toxic Epidermal Necrolysis}

Carbonic anhydrase inhibitor methazolamide is a medication applied in lowering intraocular pressure, for example, as a patient with glaucoma. Despite the low frequency, methazolamide may potentially induce SJS/TEN. Strong association of HLA-B*59:01 and methazolamide-induced SJS/TEN in Korean and Japanese had been reported (66) and also in Han Chinese (67) (Table 1).

\section{Jackpot Theory and Importance of Specific T Cell Receptor for the Development of Severe Cutaneous Adverse Reactions}

Although previous studies proved the association of specific HLA genotypes with SCARs, the positive predictive values were mostly low (81). Our previous study showed CBZ-specific T cells expressing specific TCR from peripheral blood mononuclear cells and causing activation of granulysin release in HLAB*15:02-positive CBZ-induced SJS/TEN but was not found in CBZ-tolerant individuals or other drug-related SJS/TEN (82). Similarly, preferential usage of TCR $\beta$ variable gene and clonal expansion of specific third complementarity-determining region (CDR3) was identified in blister cells of patients with allopurinolinduced SJS/TEN (83). More recently, our further study showed a public $\alpha \beta T C R$ was further identified from CTLs of patients with CBZ-induced SJS/TEN, with a paired TCR $\beta$ CDR3 clonotype "ASSLAGELF" and TCR $\alpha$ CDR3 clonotype "VFDNTDKLI," which react to CBZ and its structural analogs by its structural analogs and bind affinity and mediate immune response (84). Importantly, the specific CDR3 clonotype was present in CTLs of CBZ-induced SJS/TEN of patients from different populations (Chinese or Europeans) with or without the HLA-B*1502 genotype. The finding of clonotype-specific $\mathrm{T}$ cell and drugspecific public TCR in patients illustrated the essential molecular role of shared and restricted TCR that interacted with specific HLA and drugs for the development of SCARs (Jackpot theory). 


\section{Pharmacogenomic Test for Prevention of Severe Cutaneous Adverse Reactions}

The burden of developing SCARs was life-threatening. Not only public health but also medical resources were affected. A team in Singapore observed higher laboratory costs in the residency of patients with ADRs (85).

Considering the mortality rate and economic burden of SCARs, an easy and effective method for the prevention of SCARs would be greatly needed. The development of a strong correlation of preemptive genetic tests for high-risk medications related to SCARs is therefore very helpful. By screening relevant genes before using susceptible culprit drugs, we should be able to prevent the occurrence of SCARs and the consequent cost for sequalae.

Genetic testing of HLA-B*15:02 before CBZ was warned by The Food and Drug Administration (FDA) of the United States, Taiwan, and similar agencies of other countries (86), and genetic testing of HLA-B*58:01 before allopurinol initiation was warned by the FDA of Taiwan or other Asian countries (Table 1). Recommendations of relative gene testing before culprit drugs in case of developing SCARs were noticed in various studies (87). The first prospective screening test was applied in patients with HIV infection needed for abacavir and demonstrated a significantly lower incidence in the HLA-B*57:01 screening group (74). For proof of concept and clinical implementation, the Taiwan SJS Consortium had conducted a clinical trial to prevent CBZ-induced SCARs by genotyping DNA with HLA$B^{*}$ 15:02 allele of 4,877 candidates before CBZ therapy and found no SJS/TEN with negative subjects (88). The other one of the most commonly used drugs and cause of SCARs in Taiwan was allopurinol. Prospective screening with HLA-B*58:01 enrolled 2,926 patients before initiation of allopurinol in Taiwan, and the result showed none of the negative subjects developed SCAR (89). Recently, a prospective study of 1,539 patients diagnosed with leprosy underwent HLA-B*13:01 genotyping before using dapsone in China, and the result showed no SCARs developed in non-carrier (90) (Table 1).

\section{Implementation of Precision-Based Use of Antiepileptic Drug Therapy by Screening Multiple Risk Alleles Related to Aromatic Antiepileptic Drugs for Prevention of Severe Cutaneous Adverse Reactions}

With a similar aromatic ring structure, the first line AEDs, such as CBZ, OXC, LTG, PHT, and PB, have potential and share similar risk alleles predisposing to SCARs. For consideration of efficacy and safety for clinical selection of AEDs, a piece of pharmacogenomics information is important for decision making for patients with epileptic or neurologic disorders. Therefore, pharmacogenomic panel testing for multiple risk alleles related to all AEDs has its clinical necessity and demand; for clinical implementation and to evaluate the feasibility and efficacy of a pharmacogenomic panel of AEDs, we have developed a rapid testing panel of multiple risk alleles, including HLA-B*15:02, CYP2C9*3, HLA-B*13:01, HLA-B*51:01, and
TABLE 2 | Pharmacogenomic panel linked to AED-related SCARs in Asians.

\begin{tabular}{llccc}
\hline & Risk alleles & Sensitivity (\%) & Specificity (\%) & Reference \\
\hline CBZ-SCARs & $\begin{array}{l}\text { HLA-B } \\
\text { HLA-A } 15: 02\end{array}$ & 74.6 & 90.3 & $(31)$ \\
OXC-SCARs & HLA-B ${ }^{\star} 15: 02$ & 70.6 & 92.1 & $(23)$ \\
PHT-SCARs & HLA-B ${ }^{\star} 15: 02$ & 71.9 & 77.7 & $(37)$ \\
& HLA-B $13: 01$ & & & \\
& HLA-B $51: 01$ & & & \\
& CYP2C9*3 & & & \\
LTG-SCARs & HLA-B ${ }^{\star} 15: 02$ & 29.4 & & \\
\hline
\end{tabular}

HLA-A*31:01, which are strongly related to aromatic AEDinduced SCARs (Table 2) for decision making before initiating AEDs. A clinical trial has started since 2018 in Taiwan and China of multiple medical centers, by enrolling patients with need of antiepileptic drugs without history of using, and performing the testing panel by quantitative polymerase chain reaction (qPCR). With avoiding relevant drugs with positive susceptible genes, a preliminary evaluation of 231 patients with negative corresponding risk alleles received aromatic AEDs therapy, no SCARs have been observed, although five patients developed milder maculopapular eruption or itchy skin lesions.

\section{CONCLUSIONS}

SCARs are rare but life-threatening. The findings of the relationship with susceptible genes and drugs lead to clinical applications of prevention. By screening the known relevant genes before prescribing potentially culprit drugs in corresponding ethnicities would be an effective method to avoid the development of SCARs.

\section{AUTHOR CONTRIBUTIONS}

S-CY, M-YL, Z-YZ, X-YJ, MH, Y-FZ, C-BC, and W-HC wrote the original draft. $\mathrm{X}-\mathrm{YJ}, \mathrm{MH}$, and $\mathrm{Y}-\mathrm{FZ}$ provided the resources. S-CY, M-YL, Z-YZ, C-BC, and W-HC reviewed and edited the draft. $\mathrm{C}-\mathrm{BC}$ and $\mathrm{W}-\mathrm{HC}$ conceptualized the review and acquired funding. All authors contributed to the article and approved the submitted version.

\section{FUNDING}

This study was supported by research grants from the Xiamen Science and Technology Bureau, China (3502Z20180411), Xiamen Chang Gung Hospital (3502Z20180411), the Ministry of Science and Technology, Taiwan (MOST 108-2314-B-182A-006-MY3 to C-BC; MOST 103-2321B-182-001, MOST 104-2314-B-182A-148-MY3, MOST 104-2325-B-182A-006, MOST 105-2325-B-182A-007, MOST 106-2314-B-182A-037-MY3, MOST 106-2622-B-182A-003CC2, MOST 107-2622-B-182A-001-CC2, MOST 108-23 14-B-182A-104-MY3, MOST 108-2320-B-182A-023-MY3, 
MOST 108-2320-B-182A-024-MY2, MOST 109-2320-B182A-008 -MY3, MOST-108-2314-B-182A-104 -MY3, and MOST-109-2326-B-182A-001 to W-HC), and Chang Gung Memorial Hospital, Taiwan (CMRPG2H0081, CMRPG2J0221, CMRPG2J0222, NMRPG2J6012, NMRPG2J6013, CIRPG2I0011, CIRPG2I0012, CIRPG2I0013 to C-BC; CIRPG3I0022,

\section{REFERENCES}

1. Chung WH, Wang CW, Dao RL. Severe cutaneous adverse drug reactions. $J$ Dermatol. (2016) 43:758-66. doi: 10.1111/1346-8138.13430

2. Sunaga Y, Kurosawa M, Ochiai H, Watanabe H, Sueki H, Azukizawa H, et al. The nationwide epidemiological survey of Stevens-Johnson syndrome and toxic epidermal necrolysis in Japan, 2016-2018. J Dermatol Sci. (2020) 100:175-82. doi: 10.1016/j.jdermsci.2020.09.009

3. Yang MS, Lee JY, Kim J, Kim GW, Kim BK, Kim JY, et al. Searching for the culprit drugs for Stevens-Johnson syndrome and toxic epidermal necrolysis from a nationwide claim database in Korea. J Allergy Clin Immunol Pract. (2020) 8:690-5 e692. doi: 10.1016/j.jaip.2019.09.032

4. Yang SC, Hu S, Zhang SZ, Huang JW, Zhang J, Ji C, et al. The epidemiology of Stevens-Johnson syndrome and toxic epidermal necrolysis in China. $J$ Immunol Res. (2018) 2018:4320195. doi: 10.1155/2018/4154507

5. Dodiuk-Gad RP, Chung WH, Valeyrie-Allanore L, Shear NH. StevensJohnson syndrome and toxic epidermal necrolysis: an update. Am J Clin Dermatol. (2015) 16:475-93. doi: 10.1007/s40257-015-0158-0

6. Wedi B. Definitions and mechanisms of drug hypersensitivity. Expert Rev Clin Pharmacol. (2010) 3:539-51. doi: 10.1586/ecp.10.32

7. Chung WH, Hung SI. Recent advances in the genetics and immunology of Stevens-Johnson syndrome and toxic epidermal necrosis. J Dermatol Sci. (2012) 66:190-6. doi: 10.1016/j.jdermsci.2012.04.002

8. Chung WH, Hung SI, Yang JY, Su SC, Huang SP, Wei CY, et al. Granulysin is a key mediator for disseminated keratinocyte death in Stevens-Johnson syndrome and toxic epidermal necrolysis. Nat Med. (2008) 14:1343-50. doi: $10.1038 / \mathrm{nm} .1884$

9. Kardaun SH, Sekula P, Valeyrie-Allanore L, Liss Y, Chu CY, Creamer D, et al. Drug reaction with eosinophilia and systemic symptoms (DRESS): an original multisystem adverse drug reaction. Results from the prospective RegiSCAR study. Br J Dermatol. (2013) 169:1071-80. doi: 10.1111/bjd. 12501

10. Komatsu-Fujii T, Kaneko S, Chinuki Y, Suyama Y, Ohta M, Niihara H, et al. Serum TARC levels are strongly correlated with blood eosinophil count in patients with drug eruptions. Allergol Int. (2017) 66:116-22. doi: 10.1016/j.alit.2016.06.003

11. Roujeau JC, Bracq C, Huyn NT, Chaussalet E, Raffin C, Duedari N. HLA phenotypes and bullous cutaneous reactions to drugs. Tissue Antigens. (1986) 28:251-4. doi: 10.1111/j.1399-0039.1986.tb00491.x

12. Roujeau JC, Huynh TN, Bracq C, Guillaume JC, Revuz J, Touraine R. Genetic susceptibility to toxic epidermal necrolysis. Arch Dermatol. (1987) 123:11713.

13. Chang CJ, Chen CB, Hung SI, Ji C, Chung WH. Pharmacogenetic testing for prevention of severe cutaneous adverse drug reactions. Front Pharmacol. (2020) 11:969. doi: 10.3389/fphar.2020.00969

14. Aihara M. Pharmacogenetics of cutaneous adverse drug reactions. J Dermatol. (2011) 38:246-54. doi: 10.1111/j.1346-8138.2010.01196.x

15. Tong H, Phan NVT, Nguyen TT, Nguyen DV, Vo NS, Le L. Review on databases and bioinformatic approaches on pharmacogenomics of adverse drug reactions. Pharmgenomics Pers Med. (2021) 14:61-75. doi: 10.2147/PGPM.S290781

16. Ueta M. Results of detailed investigations into stevens-johnson syndrome with severe ocular complications. Invest Ophthalmol Vis Sci. (2018) 59:DES183DES191. doi: 10.1167/iovs.17-23537

17. Wang CW, Tassaneeyakul W, Chen CB, Chen WT, Teng YC, Huang CY, et al. Whole genome sequencing identifies genetic variants associated with co-trimoxazole hypersensitivity in Asians. J Allergy Clin Immunol. (2021). 147:1402-12. doi: 10.1016/j.jaci.2020.08.003
CIRPG3I0023, CIRPG3I0042, CIRPG3I0043, CLRPG3E0036, CLRPG3J0012, CMRPG3I0382, CORPG3J0322, CLRPG2E0053, CMRPG3D0363, CORPG3F0042 3, NCRPG3G0023, NCRPG3GS023, NMRPG3G6293, NMRPG3J6062, NMRPG3J6063, NMRPG3K0521, and OMRPG3E0041 to $\mathrm{W}-\mathrm{HC})$.
18. Chung WH, Hung SI, Hong HS, Hsih MS, Yang LC, Ho HC, et al. Medical genetics: a marker for Stevens-Johnson syndrome. Nature. (2004) 428:486. doi: $10.1038 / 428486 a$

19. Tassaneeyakul W, Tiamkao S, Jantararoungtong T, Chen P, Lin SY, Chen WH, et al. Association between HLA-B*1502 and carbamazepine-induced severe cutaneous adverse drug reactions in a Thai population. Epilepsia. (2010) 51:926-30. doi: 10.1111/j.1528-1167.2010.02533.x

20. Chang CC, Too CL, Murad S, Hussein SH. Association of HLA-B*1502 allele with carbamazepine-induced toxic epidermal necrolysis and Stevens-Johnson syndrome in the multi-ethnic Malaysian population. Int J Dermatol. (2011) 50:221-4. doi: 10.1111/j.1365-4632.2010.04745.x

21. Mehta TY, Prajapati LM, Mittal B, Joshi CG, Sheth JJ, Patel DB, et al. Association of HLA-B*1502 allele and carbamazepine-induced StevensJohnson syndrome among Indians. Indian J Dermatol Venereol Leprol. (2009) 75:579-82. doi: 10.4103/0378-6323.57718

22. Man CB, Kwan P, Baum L, Yu E, Lau KM, Cheng AS, et al. Association between HLA-B*1502 allele and antiepileptic drug-induced cutaneous reactions in Han Chinese. Epilepsia. (2007) 48:1015-8. doi: 10.1111/j.1528-1167.2007.01022.x

23. Chen CB, Hsiao YH, Wu T, Hsih MS, Tassaneeyakul W, Jorns TP, et al. Risk and association of HLA with oxcarbazepine-induced cutaneous adverse reactions in Asians. Neurology. (2017) 88:78-86. doi: 10.1212/WNL.0000000000003453

24. Chang CC, Ng CC, Too CL, Choon SE, Lee CK, Chung WH, et al. Association of HLA-B*15:13 and HLA-B* 15:02 with phenytoin-induced severe cutaneous adverse reactions in a Malay population. Pharmacogenomics J. (2017) 17:1703. doi: $10.1038 /$ tpj. 2016.10

25. Hung SI, Chung WH, Liu ZS, Chen CH, Hsih MS, Hui RC, et al. Common risk allele in aromatic antiepileptic-drug induced Stevens-Johnson syndrome and toxic epidermal necrolysis in Han Chinese. Pharmacogenomics. (2010) 11:349-56. doi: 10.2217/pgs.09.162

26. Locharernkul C, Loplumlert J, Limotai C, Korkij W, Desudchit T, Tongkobpetch S, et al. Carbamazepine and phenytoin induced StevensJohnson syndrome is associated with HLA-B*1502 allele in Thai population. Epilepsia. (2008) 49:2087-91. doi: 10.1111/j.1528-1167.2008. 01719.x

27. Kaniwa N, Saito Y, Aihara M, Matsunaga K, Tohkin M, Kurose K, et al. HLA-B*1511 is a risk factor for carbamazepine-induced Stevens-Johnson syndrome and toxic epidermal necrolysis in Japanese patients. Epilepsia. (2010) 51:2461-5. doi: 10.1111/j.1528-1167.2010.02766.x

28. Kim SH, Lee KW, Song WJ, Kim SH, Jee YK, Lee SM, et al. Carbamazepineinduced severe cutaneous adverse reactions and HLA genotypes in Koreans. Epilepsy Res. (2011) 97:190-7. doi: 10.1016/j.eplepsyres.2011. 08.010

29. Jaruthamsophon K, Tipmanee V, Sangiemchoey A, Sukasem C, Limprasert P. HLA-B ${ }^{\star}$ 15:21 and carbamazepine-induced Stevens-Johnson syndrome: pooled-data and in silico analysis. Sci Rep. (2017) 7:45553. doi: $10.1038 /$ srep45553

30. Mockenhaupt M, Wang CW, Hung SI, Sekula P, Schmidt AH, Pan RY, et al. HLA-B*57:01 confers genetic susceptibility to carbamazepineinduced SJS/TEN in Europeans. Allergy. (2019) 74:2227-30. doi: 10.1111/all. 13821

31. Genin E, Chen DP, Hung SI, Sekula P, Schumacher M, Chang PY, et al. HLA-A*31:01 and different types of carbamazepine-induced severe cutaneous adverse reactions: an international study and meta-analysis. Pharmacogenomics J. (2014) 14:281-8. doi: 10.1038/tpj.2013.40

32. McCormack M, Alfirevic A, Bourgeois S, Farrell JJ, Kasperaviciute D, Carrington $M$, et al. HLA-A*3101 and carbamazepine-induced 
hypersensitivity reactions in Europeans. N Engl J Med. (2011) 364:1134-43. doi: 10.1056/NEJMoa1013297

33. Mushiroda T, Takahashi Y, Onuma T, Yamamoto Y, Kamei T, Hoshida T, et al. Association of HLA-A*31:01 screening with the incidence of carbamazepineinduced cutaneous adverse reactions in a Japanese population. JAMA Neurol. (2018) 75:842-9. doi: 10.1001/jamaneurol.2018.0278

34. Lonjou C, Borot N, Sekula P, Ledger N, Thomas L, Halevy S, et al. A European study of HLA-B in Stevens-Johnson syndrome and toxic epidermal necrolysis related to five high-risk drugs. Pharmacogenet Genom. (2008) 18:99-107. doi: 10.1097/FPC.0b013e3282f3ef9c

35. Chung WH, Chang WC, Lee YS, Wu YY, Yang CH, Ho HC, et al. Genetic variants associated with phenytoin-related severe cutaneous adverse reactions. JAMA. (2014) 312:525-34. doi: 10.1001/jama.2014.7859

36. Kaniwa N, Sugiyama E, Saito Y, Kurose K, Maekawa K, Hasegawa $\mathrm{R}$, et al. Specific HLA types are associated with antiepileptic druginduced Stevens-Johnson syndrome and toxic epidermal necrolysis in Japanese subjects. Pharmacogenomics. (2013) 14:1821-31. doi: 10.2217/pgs. 13.180

37. Su SC, Chen CB, Chang WC, Wang CW, Fan WL, Lu LY, et al. HLA Alleles and $\mathrm{CYP} 2 \mathrm{C}{ }^{*} 3$ as predictors of phenytoin hypersensitivity in East Asians. Clin Pharmacol Ther. (2019) 105:476-85. doi: 10.1002/cpt.1190

38. Rutkowski K, Taylor C, Wagner A. HLA B62 as a possible risk factor for drug reaction with eosinophilia and systemic symptoms to piperacillin/tazobactam. J Allergy Clin Immunol Pract. (2017) 5:829-30. doi: 10.1016/j.jaip.2016.10.008

39. Konvinse KC, Trubiano JA, Pavlos R, James I, Shaffer CM, Bejan CA, et al. HLA-A*32:01 is strongly associated with vancomycin-induced drug reaction with eosinophilia and systemic symptoms. J Allergy Clin Immunol. (2019) 144:183-92. doi: 10.1016/j.jaci.2019.01.045

40. Hetherington S, Hughes AR, Mosteller M, Shortino D, Baker KL, Spreen W, et al. Genetic variations in HLA-B region and hypersensitivity reactions to abacavir. Lancet. (2002) 359:1121-2. doi: 10.1016/S0140-6736(02)08158-8

41. Mallal S, Nolan D, Witt C, Masel G, Martin AM, Moore C, et al. Association between presence of HLA-B*5701, HLA-DR7, and HLA-DQ3 and hypersensitivity to HIV-1 reverse-transcriptase inhibitor abacavir. Lancet. (2002) 359:727-32. doi: 10.1016/S0140-6736(02)07873-X

42. Hughes AR, Mosteller M, Bansal AT, Davies K, Haneline SA, Lai EH, et al. Association of genetic variations in HLA-B region with hypersensitivity to abacavir in some, but not all, populations. Pharmacogenomics. (2004) 5:20311. doi: 10.1517/phgs.5.2.203.27481

43. Manglani MV, Gabhale YR, Lala MM, Sekhar R, More D. HLAB*5701 allele in HIV-infected indian children and its association with abacavir hypersensitivity. Indian Pediatr. (2018) 55:140-1. doi: $10.1007 / \mathrm{s} 13312-018-1248-\mathrm{x}$

44. Chantarangsu S, Mushiroda T, Mahasirimongkol S, Kiertiburanakul S, Sungkanuparph S, Manosuthi W, et al. HLA-B*3505 allele is a strong predictor for nevirapine-induced skin adverse drug reactions in HIVinfected Thai patients. Pharmacogenet Genomics. (2009) 19:139-46. doi: 10.1097/FPC.0b013e32831d0faf

45. Carr DF, Bourgeois S, Chaponda M, Takeshita LY, Morris AP, Castro EM, et al. (2017). Genome-wide association study of nevirapine hypersensitivity in a sub-Saharan African HIV-infected population. J Antimicrob Chemother. 72:1152-62. doi: 10.1093/jac/dkw545

46. Yuan J, Guo S, Hall D, Cammett AM, Jayadev S, Distel M, et al. Toxicogenomics of nevirapine-associated cutaneous and hepatic adverse events among populations of African, Asian, and European descent. AIDS. (2011) 25:1271-80. doi: 10.1097/QAD.0b013e32834779df

47. Littera R, Carcassi C, Masala A, Piano P, Serra P, Ortu F, et al. HLAdependent hypersensitivity to nevirapine in Sardinian HIV patients. AIDS. (2006) 20:1621-6. doi: 10.1097/01.aids.0000238408.82947.09

48. Gatanaga H, Yazaki H, Tanuma J, Honda M, Genka I, Teruya K, et al. HLACw8 primarily associated with hypersensitivity to nevirapine. AIDS. (2007) 21:264-5. doi: 10.1097/QAD.0b013e32801199d9

49. Martin AM, Nolan D, James I, Cameron P, Keller J, Moore C, et al. Predisposition to nevirapine hypersensitivity associated with HLADRB1*0101 and abrogated by low CD4 T-cell counts. AIDS. (2005) 19:97-9. doi: 10.1097/00002030-200501030-00014

50. Thomas M, Hopkins C, Duffy E, Lee D, Loulergue P, Ripamonti D, et al. Association of the HLA-B*53:01 allele with drug reaction with eosinophilia and systemic symptoms (DRESS) syndrome during treatment of HIV infection with Raltegravir. Clin Infect Dis. (2017) 64:1198-203. doi: 10.1093/cid/cix096

51. Zhang FR, Liu H, Irwanto A, Fu XA, Li Y, Yu GQ, et al. HLA-B*13:01 and the dapsone hypersensitivity syndrome. N Engl J Med. (2013) 369:1620-8. doi: 10.1056/NEJMoa1213096

52. Park HJ, Park JW, Kim SH, Choi SY, Kim HK, Jung CG, et al. The HLA$B^{*}$ 13:01 and the dapsone hypersensitivity syndrome in Korean and Asian populations: genotype- and meta-analyses. Expert Opin Drug Saf. (2020) 19:1349-56. doi: 10.1080/14740338.2020.1796965

53. Krismawati H, Irwanto A, Pongtiku A, Irwan ID, Maladan Y, Sitanggang YA, et al. Validation study of HLA-B*13:01 as a biomarker of dapsone hypersensitivity syndrome in leprosy patients in Indonesia. PLoS Negl Trop Dis. (2020) 14:e0008746. doi: 10.1371/journal.pntd.0008746

54. Tempark T, Satapornpong P, Rerknimitr P, Nakkam N, Saksit N, Wattanakrai $\mathrm{P}$, et al. Dapsone-induced severe cutaneous adverse drug reactions are strongly linked with HLA-B*13: 01 allele in the Thai population. Pharmacogenet Genomics. (2017) 27:429-37. doi: 10.1097/FPC.0000000000000306

55. Ueta M, Kaniwa N, Sotozono C, Tokunaga K, Saito Y, Sawai H, et al. Independent strong association of HLA-A*02:06 and HLA-B*44:03 with cold medicine-related Stevens-Johnson syndrome with severe mucosal involvement. Sci Rep. (2014) 4:4862. doi: 10.1038/srep04862

56. Ueta M, Kannabiran C, Wakamatsu TH, Kim MK, Yoon KC, Seo KY, et al. Trans-ethnic study confirmed independent associations of HLA$A^{*}$ 02:06 and HLA-B*44:03 with cold medicine-related Stevens-Johnson syndrome with severe ocular surface complications. Sci Rep. (2014) 4:5981. doi: 10.1038/srep05981

57. Jun I, Rim JH, Kim MK, Yoon KC, Joo CK, Kinoshita S, et al. Association of human antigen class I genes with cold medicine-related Stevens-Johnson syndrome with severe ocular complications in a Korean population. $\mathrm{Br} \mathrm{J}$ Ophthalmol. (2019) 103:573-6. doi: 10.1136/bjophthalmol-2018-313263

58. Wakamatsu TH, Ueta M, Tokunaga K, Okada Y, Loureiro RR, Costa KA, et al. Human leukocyte antigen class i genes associated with StevensJohnson syndrome and severe ocular complications following use of cold medicine in a Brazilian Population. JAMA Ophthalmol. (2017) 135:355-60. doi: 10.1001/jamaophthalmol.2017.0074

59. Jongkhajornpong P, Lekhanont K, Pisuchpen P, Chantaren P, Puangsricharern V, Prabhasawat P, et al. Association between HLA-B*44:03-HLA-C* 07:01 haplotype and cold medicine-related Stevens-Johnson syndrome with severe ocular complications in Thailand. Br J Ophthalmol. (2018) 102:1303-7. doi: 10.1136/bjophthalmol-2017-311823

60. Ueta M, Sotozono C, Nakano M, Taniguchi T, Yagi T, Tokuda $Y$, et al. Association between prostaglandin $\mathrm{E}$ receptor 3 polymorphisms and Stevens-Johnson syndrome identified by means of a genome-wide association study. J Allergy Clin Immunol. (2010) 126:1218-25.e1210. doi: 10.1016/j.jaci.2010.08.007

61. Ueta M, Sawai H, Sotozono C, Hitomi Y, Kaniwa N, Kim MK, et al. (2015). IKZF1, a new susceptibility gene for cold medicine-related Stevens-Johnson syndrome/toxic epidermal necrolysis with severe mucosal involvement. J Allergy Clin Immunol. 135:1538-45.e1517. doi: 10.1016/j.jaci.2014. 12.1916

62. Tassaneeyakul W, Jantararoungtong T, Chen P, Lin PY, Tiamkao S, Khunarkornsiri U, et al. Strong association between HLA-B*5801 and allopurinol-induced Stevens-Johnson syndrome and toxic epidermal necrolysis in a Thai population. Pharmacogenet Genomics. (2009) 19:704-9. doi: 10.1097/FPC.0b013e328330a3b8

63. Kaniwa N, Saito Y, Aihara M, Matsunaga K, Tohkin M, Kurose K, et al. HLA-B locus in Japanese patients with anti-epileptics and allopurinol-related StevensJohnson syndrome and toxic epidermal necrolysis. Pharmacogenomics. (2008) 9:1617-22. doi: 10.2217/14622416.9.11.1617

64. Hung SI, Chung WH, Liou LB, Chu CC, Lin M, Huang HP, et al. HLA-B*5801 allele as a genetic marker for severe cutaneous adverse reactions caused by allopurinol. Proc Natl Acad Sci USA. (2005) 102:4134-9. doi: 10.1073/pnas.0409500102

65. Kang HR, Jee YK, Kim YS, Lee $\mathrm{CH}$, Jung JW, Kim SH, et al. Positive and negative associations of HLA class I alleles with allopurinolinduced SCARs in Koreans. Pharmacogenet Genomics. (2011) 21:303-7. doi: 10.1097/FPC.0b013e32834282b8 
66. Kim SH, Kim M, Lee KW, Kim SH, Kang HR, Park HW, et al. HLAB*5901 is strongly associated with methazolamide-induced Stevens-Johnson syndrome/toxic epidermal necrolysis. Pharmacogenomics. (2010) 11:879-84. doi: $10.2217 /$ pgs. 10.54

67. Yang F, Xuan J, Chen J, Zhong H, Luo H, Zhou P, et al. HLA-B*59:01: a marker for Stevens-Johnson syndrome/toxic epidermal necrolysis caused by methazolamide in Han Chinese. Pharmacogenomics J. (2016) 16:83-7. doi: 10.1038/tpj.2015.25

68. Wang W, Hu FY, Wu XT, An DM, Yan B, Zhou D. Genetic predictors of Stevens-Johnson syndrome and toxic epidermal necrolysis induced by aromatic antiepileptic drugs among the Chinese Han population. Epilepsy Behav. (2014) 37:16-9. doi: 10.1016/j.yebeh.2014.05.025

69. Cheung YK, Cheng SH, Chan EJ, Lo SV, Ng MH, Kwan P. HLA-B alleles associated with severe cutaneous reactions to antiepileptic drugs in Han Chinese. Epilepsia. (2013) 54:1307-14. doi: 10.1111/epi.12217

70. Ozeki T, Mushiroda T, Yowang A, Takahashi A, Kubo M, Shirakata Y, et al. Genome-wide association study identifies HLA-A ${ }^{\star} 3101$ allele as a genetic risk factor for carbamazepine-induced cutaneous adverse drug reactions in Japanese population. Hum Mol Genet. (2011) 20:1034-41. doi: $10.1093 / \mathrm{hmg} / \mathrm{ddq} 537$

71. Blumenthal KG, Peter JG, Trubiano JA, Phillips EJ. Antibiotic allergy. Lancet. (2019) 393:183-98. doi: 10.1016/S0140-6736(18) 32218-9

72. Norton AE, Konvinse K, Phillips EJ, Broyles AD. Antibiotic allergy in pediatrics. Pediatrics. (2018) 141:e20172497. doi: 10.1542/peds.2017-2497

73. Rodriguez-Novoa S, Soriano V. Current trends in screening across ethnicities for hypersensitivity to abacavir. Pharmacogenomics. (2008) 9:1531-41. doi: 10.2217/14622416.9.10.1531

74. Mallal S, Phillips E, Carosi G, Molina JM, Workman C, Tomazic J, et al. HLA-B*5701 screening for hypersensitivity to abacavir. N Engl J Med. (2008) 358:568-79. doi: 10.1056/NEJMoa0706135

75. To SW, Chen JH, Wong KH, Chan KC, Tsang OT, Yam WC. HLA-B*5701 genetic screening among HIV-1 infected patients in Hong Kong: is this a practical approach in Han-Chinese? Int J STD AIDS. (2013) 24:50-2. doi: 10.1258/ijsa.2012.012102

76. Gao S, Gui XE, Liang K, Liu Z, Hu J, Dong B. HLA-dependent hypersensitivity reaction to nevirapine in Chinese Han HIV-infected patients. AIDS Res Hum Retroviruses. (2012) 28:540-3. doi: 10.1089/aid.20 11.0107

77. Chantarangsu S, Mushiroda T, Mahasirimongkol S, Kiertiburanakul S, Sungkanuparph S, Manosuthi W, et al. Genome-wide association study identifies variations in 6p21.3 associated with nevirapine-induced rash. Clin Infect Dis. (2011) 53:341-8. doi: 10.1093/cid/cir403

78. Nakatani K, Ueta M, Khor SS, Hitomi Y, Okudaira Y, Masuya $A$, et al. Identification of HLA-A $^{*} 02: 06: 01$ as the primary disease susceptibility HLA allele in cold medicine-related Stevens-Johnson syndrome with severe ocular complications by high-resolution NGSbased HLA typing. Sci Rep. (2019) 9:16240. doi: 10.1038/s41598-01952619-2

79. Yu KH, Yu CY, Fang YF. Diagnostic utility of HLA-B*5801 screening in severe allopurinol hypersensitivity syndrome: an updated systematic review and meta-analysis. Int J Rheum Dis. (2017) 20:1057-71. doi: 10.1111/1756-185X.13143
80. Wang CW, Dao RL, Chung WH. Immunopathogenesis and risk factors for allopurinol severe cutaneous adverse reactions. Curr Opin Allergy Clin Immunol. (2016) 16:339-45. doi: 10.1097/ACI.0000000000000286

81. Pan RY, Dao RL, Hung SI, Chung WH. Pharmacogenomic advances in the prediction and prevention of cutaneous idiosyncratic drug reactions. Clin Pharmacol Ther. (2017) 102:86-97. doi: 10.1002/cpt.683

82. Ko TM, Chung WH, Wei CY, Shih HY, Chen JK, Lin CH, et al. Shared and restricted T-cell receptor use is crucial for carbamazepine-induced StevensJohnson syndrome. J Allergy Clin Immunol. (2011) 128:1266-76 e1211. doi: 10.1016/j.jaci.2011.08.013

83. Chung WH, Pan RY, Chu MT, Chin SW, Huang YL, Wang WC, et al. Oxypurinol-specific T cells possess preferential TCR clonotypes and express granulysin in allopurinol-induced severe cutaneous adverse reactions. J Invest Dermatol. (2015) 135:2237-48. doi: 10.1038/jid.2015.165

84. Pan RY, Chu MT, Wang CW, Lee YS, Lemonnier F, Michels AW, et al. Identification of drug-specific public TCR driving severe cutaneous adverse reactions. Nat Commun. (2019) 10:3569. doi: 10.1038/s41467-019-11396-2

85. Chan SL, Ng HY, Sung C, Chan A, Winther MD, Brunham LR, et al. Economic burden of adverse drug reactions and potential for pharmacogenomic testing in Singaporean adults. Pharmacogenomics J. (2019) 19:401-410. doi: 10.1038/s41397-018-0053-1

86. Ferrell PB Jr, McLeod HL. Carbamazepine, HLA-B*1502 and risk of Stevens-Johnson syndrome and toxic epidermal necrolysis: US FDA recommendations. Pharmacogenomics. (2008) 9:1543-6. doi: $10.2217 / 14622416.9 .10 .1543$

87. Khor AH, Lim KS, Tan CT, Kwan Z, Tan WC, Wu DB, et al. HLA$A^{*} 31: 01$ and HLA-B*15:02 association with Stevens-Johnson syndrome and toxic epidermal necrolysis to carbamazepine in a multiethnic Malaysian population. Pharmacogenet Genomics. (2017) 27:275-8. doi: 10.1097/FPC.0000000000000287

88. Chen P, Lin JJ, Lu CS, Ong CT, Hsieh PF, Yang CC, et al. Carbamazepineinduced toxic effects and HLA-B*1502 screening in Taiwan. N Engl J Med. (2011) 364:1126-33. doi: 10.1056/NEJMoa1009717

89. Ko TM, Tsai CY, Chen SY, Chen KS, Yu KH, Chu CS, et al. Use of HLA-B*58:01 genotyping to prevent allopurinol induced severe cutaneous adverse reactions in Taiwan: national prospective cohort study. BMJ. (2015) 351:h4848. doi: 10.1136/bmj.h4848

90. Liu H, Wang Z, Bao F, Wang C, Sun L, Zhang H, et al. Evaluation of prospective HLA-B*13:01 screening to prevent dapsone hypersensitivity syndrome in patients with leprosy. JAMA Dermatol. (2019) 155:666-72. doi: 10.1001/jamadermatol.2018.5360

Conflict of Interest: The authors declare that the research was conducted in the absence of any commercial or financial relationships that could be construed as a potential conflict of interest.

Copyright (c) 2021 Yang, Chen, Lin, Zhang, Jia, Huang, Zou and Chung. This is an open-access article distributed under the terms of the Creative Commons Attribution License (CC BY). The use, distribution or reproduction in other forums is permitted, provided the original author(s) and the copyright owner(s) are credited and that the original publication in this journal is cited, in accordance with accepted academic practice. No use, distribution or reproduction is permitted which does not comply with these terms. 